
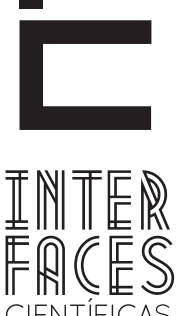

CIENTÍFICAS

HUMANASE SOCIAIS

ISSN IMPRESSO 2316-3348

E-ISSN 2316-3801

DOI - 10.17564/2316-3801.2019v7n3p21-32

\title{
EROTISMO EM CONTEXTOS (DÊS) INSTITUCIONAIS: AEROMOÇAS DA VARIG NA PLAYBOY
}

\author{
EROTISM IN (DE) INSTITUTIONAL CONTEXTS: VARIG FLIGHT ATTENDANTS AT PLAYBOY MAGAZINE \\ EROTISMO EN CONTEXTOS (DES) INSTITUCIONALES: AZAFATAS DE LA VARIG EN LA PLAYBOY
}

Carolina Castellitti ${ }^{1}$

\section{RESUMO}

0 presente artigo realiza uma análise antropológica de um ensaio fotográfico realizado por três aeromoças da Varig para a revista Playboy, em 2006. Além das fotos, o material empírico analisado (jornais e blogs) problematiza a repercussão pública do ensaio, a partir do contraste com os discursos das protagonistas. Em diálogo com os debates do pensamento feminista dos anos 1960 e 1970, recuperando algumas contribuições contemporâneas relativas à noção de agência nos estudos de gênero, dou atenção ao contexto das fotos assim como às falas das protagonistas, para problematizar a imagem de vítimas produzida pela mídia. Espero, desse modo, contribuir com uma perspectiva que, em lugar de pensar as desigualdades de gênero de um modo rígido, considere a posição social dos sujeitos nas hierarquias múltiplas de poder, para enxergar outros tipos de desejos, vontades, estratégias e agências.

\section{PALAVRAS-CHAVE}

Aeromoças. Erotismo. Gênero. Agência. 


\section{ABSTRACT}

This article performs an anthropological analysis of a photographic essay of three Varig flight attendants for Playboy Magazine in 2006. In addition to the photos, the empirical material analyzed (newspapers, blogs) problematizes the public repercussion of the essay, by observing the contrast to the speeches of the protagonists. In a dialogue with the debates of feminist thought of the 1960 s and 1970s, and resorting to some contemporary contributions to the notion of agency in gender studies, we elucidate the context of the photographs as well as the testimonies of the protagonists, in order to question the image of victims produced by the media. We hope to contribute thus to a perspective that, instead of thinking about gender differences in a rigid manner, proposes to consider the social position of the subject in the multiple hierarchies of power, so as to see other kinds of desires, wishes, strategies and agencies.

\section{KEYWORDS}

Flight attendants. Eroticism. Gender. Agency

\section{RESUMEN}

El presente artículo realiza un análisis antropológico de un ensayo fotográfico realizado por tres azafatas de la Varig para la revista Playboy, en 2006. Además de las fotos, el material empírico analizado (periódicos, blogs) problematiza la repercusión pública del ensayo, a partir del contraste con los discursos de las protagonistas. En diálogo con los debates del pensamiento feminista de los años 1960 y 70, y recuperando algunas contribuciones contemporáneas relativas a la noción de agencia en los estudios de género, presto atención al contexto de las fotos y a los discursos de las protagonistas, para problematizar la imagen de víctimas producida por los medios. Espero, de este modo, contribuir con una perspectiva que, en lugar de pensar las desigualdades de género de un modo rígido, considere la posición de los sujetos en jerarquías múltiples de poder, para observar otros tipos de deseos, voluntades, estrategias y agencias.

\section{PALABRAS CLAVES}

Azafatas. Erotismo. Género. Agencia. 


\section{INTRODUÇ̃̃O}

O objetivo deste artigo é realizar uma análise antropológica sobre a recepção pública de um ensaio fotográfico realizado para a revista Playboy por três aeromoças da extinta companhia aérea brasileira Varig. Contrastando o relato divulgado por vários jornais com o discurso das próprias mulheres, pretendo questionar a imagem de vitimização transmitida pela mídia, trazendo para a superfície o contexto do ensaio, assim como os desejos e dificuldades por elas expressados.

Começo com uma breve descrição das fotos e algumas considerações sobre sua condição de "fetiche", a partir dos comentários de um site de sexo e entretenimento. Nesse marco, faço referência a importantes debates do pensamento feminista dos anos 1960 e 1970, da lavra de antropólogas brasileiras cuja produção se viu especialmente interpelada por esse clima intelectual e político. Posteriormente me detenho em um interlúdio teórico sobre contribuições contemporâneas relativas à noção de agência no campo dos estudos de gênero.

Por meio desses debates, pretendo mostrar as potencialidades de uma perspectiva que, em lugar de pensar as desigualdades de gênero de um modo rígido, propõe considerar a posição social dos sujeitos nas hierarquias múltiplas de poder e, desse modo, permitir enxergar desejos e possibilidades de agência muitas vezes obscurecidos e, desse modo, também obstaculizados.

0 material analisado neste artigo forma parte de uma pesquisa de doutorado sobre "A carreira de comissária de bordo na Varig: processos de autonomização feminina em contextos urbanos contemporâneos". A partir de um desenho qualitativo de tipo exploratório, utilizo a técnica de entrevistas em profundidade ${ }^{2}$ para

2 Os principais critérios para a seleção das entrevistadas foram o sexo e a idade, sendo que elas deviam estar trabalhando quando a Varig parou de funcionar, em agosto de 2006 . Todas elas tinham entre 50 e 63 anos de idade ao momento de realizar a entrevista e moravam na cidade de Rio de Janeiro. Os contatos foram realizados a partir de uma informante principal com quem a pesquisadora mantinha um vínculo antes de começar a pesquisa, e também foi utilizado o método de "bola de neve" (contatos indicados pelas mulheres que iam sendo entrevistadas). Além das entrevistas foram realizadas observações participantes em eventos que hoje em dia reúnem antigos colegas da Varig, como comemorações de aniversários, apresenta- recuperar as narrativas de mulheres que foram comissárias nessa companhia até sua falência, em agosto de 2006, procurando identificar como a trajetória profissional se projeta sob o pano de fundo de processos de desenraizamento (DUARTE; GOMES, 2008, p. 250) urbano e familiar, projetos de mobilidade social, rupturas profissionais, desemprego e envelhecimento.

A seleção e produção que a companhia realizava ao longo do curso de formação e durante a carreira, de um tipo de mulher, caracterizado por uma feminilidade sofisticada e "glamourosa", com uma ênfase particular na corporalidade e na simpatia, apontam para padrões de gênero e classe específicos do universo da aviação comercial durante a segunda metade do século XX. Apesar de específicos, esses padrões se projetam sobre o chamado processo de modernização da sociedade brasileira e constituem uma via para analisar dinâmicas de diferenciação social características das metrópoles latino americanas.

Neste artigo, tendo em conta esse projeto mais abrangente, realizo um exercício mais focalizado sobre o mencionado ensaio fotográfico realizado por três aeromoças ${ }^{3}$ da Varig em 2006 (o ano da falência da companhia), trazendo, junto às fotos, material jornalístico, comentários de blogs, e o depoimento das protagonistas realizado em uma sessão de "bate papo" do site Uol4.

Um mês antes da aparição das fotos na capa da edição de setembro de 2006 da revista Playboy, a notícia foi divulgada na coluna de Mônica Bergamo no jornal Folha de São Paulo e comentada em uma matéria na versão on-line desse jornal ${ }^{5}$. Segundo ali se informava, logo se reproduziria de forma mais ou menos invariante em

\footnotetext{
ções de livros e protestos.

30 termo "comissário de bordo" substituiu o de "aeromoço" já nos primeiros anos da institucionalização da profissão no Brasil, e é o preferido pelas mulheres que entrevistei ao longo de minha pesquisa, embora o termo "aeromoça" continue sendo utilizado pelos passageiros e seja mais presente na opinião pública não especializada em aviação. “Aeromoça” é também o termo mais utilizado no material jornalístico que analiso neste artigo.

4 Disponível em: http://tc.batepapo.uol.com.br/convidados/arquivo/ sexo/patricia-e-sabrina-ex-aeromocas-da-varig-e-capas-da-playboy-de-setembro.jhtm. Acesso em: 9 maio 2017.

5 Disponivel em: http://www1.folha.uol.com.br/folha/ilustrada/ult90u63301.shtml. Acesso em: 2 jan. 2017.
} 
outros jornais $^{6}$, Juliana Neves, Sabrina Knop e Patrícia Kreusburg, de 26, 27 e 29 anos, "todas loiras”, seriam fotografadas em um jatinho de uma empresa de táxi aéreo no final de semana para sair na capa de setembro.

Seguidamente, informava, também, que em julho a revista Playboy já tinha expressado seu interesse em realizar um ensaio de nudez com um grupo de funcionárias da Varig, e que no mesmo mês, a companhia aérea, vendida para a VarigLog, anunciara a demissão de 5.500 empregados, o que representava um corte de $58 \%$ de sua mão de obra em todo o país. Para não deixar dúvidas sobre a relação de causalidade entre esses eventos, seguidamente se afirmava que não seria a primeira vez que a revista masculina "aproveitava" o momento para "revelar a nudez" de funcionárias de uma empresa em crise: "nos EUA, em 2002, a Playboy tirou a roupa de funcionárias da Enron, empresa de energia que sofreu um colapso financeiro devido a fraudes. No mesmo ano, a situação teria se repetido com empregadas de uma empresa norte-americana de comunicações"7.

O ensaio está disponível na internet e qualquer pesquisa de imagens no Google a partir das palavras "aeromoça" e "Varig" deriva até ele. Na foto da capa, as três aeromoças aparecem vestindo lingerie preta, lenços brancos no pescoço e pequenos chapéus com distintivos característicos da aviação. Duas delas viradas de costas para a câmera e uma de frente, em um primeiro plano que apenas permite enxergar o avião que serve de cenário no fundo. No resto das fotos que compõem o ensaio, elas aparecem nuas, exceto pelo chapéu e o lenço, posando fora e dentro do avião, na cabine de comando, na saída de emergência ou nas poltronas, acompanhadas de acessórios como malas, bandejas e taças.

Quando não posam completamente nuas, os figurinos se compõem de lingeries e meias de renda, em geral pretos, sapatos de salto alto e joias como anéis, pulseiras e grandes colares dourados. 0 tipo de eroti-

6 Ver, por exemplo, http://www.gazetadopovo.com.br/economia/conteudo.phtml?id=596145. Acesso em: 2 jan. 2017.

7 Disponível em: http://www1.folha.uol.com.br/folha/ilustrada/ult90u63301.shtml. Acesso em: 2 jan. 2017. zação encenado nas fotos parece ser "fino" em oposição ao "grotesco", com importantes componentes raciais e de classe: além do fato das três mulheres serem brancas e de cabelos louros, acessórios como taças de champanhe e colares de pérolas imprimem o caráter de "glamour" então associado ao espaço da aviação comercial.

\section{OBJETO DO “FETICHE”}

Em um dos sites que disponibilizam as fotos, o Portal picante, o primeiro comentário do fórum dedicado ao assunto expressa: "esse ensaio mexe com o fetiche de muita gentec[...]”. Outra pessoa responde:

\begin{abstract}
[...] exatamente isso que eu iria comentar. Eu, inclusive, tenho esse fetiche de fazer sexo com aeromoças em pleno vôo. E esse ensaio tem até uma 'história'. Essas três moças que estão na capa da revista foram demitidas por causa da crise que o setor de aviação civil enfrentava e resolveram posar nuas para a Playboy. E hoje, espero que estejam bem ${ }^{8}$.
\end{abstract}

Foi a partir desses comentários que me coloquei algumas primeiras questões. Em que radica o caráter de "fetiche" dessas fotos? Por que importa que o ensaio tenha uma "história"?

Rogério Pires (2009) fez um mapeamento da literatura antropológica sobre os conceitos de fetiche e fetichismo, que, apesar de dar ênfase ao uso desses conceitos para pensar a religião, pode ser recuperado para pensar sua transposição à esfera da sexualidade. Segundo ele aponta de forma introdutória, fetiche denotaria inicialmente certos objetos vistos como dotados de poder sobrenatural por populações da África ocidental.

A noção de fetichismo sexual de Freud, assim como a de fetichismo da mercadoria elaborada por Marx, seriam reinvenções dessa expressão que, como Pires (2009) argumenta a partir de Pouillon, têm em comum o absurdo, a alucinação, o erro de atribuição, que faz o fetichista ver uma coisa que não está lá (FREUD), ver uma "coisa"

8 Disponível em: http://www.portalpicante.com.br/forum/viewtopic. php?f=24\&t=140. Acesso em: 2 jan. 2017. 
onde há relações sociais (MARX), ou ver um ser animado onde só há uma coisa (DE BROSSES). Em outras palavras, essas teorias compartilham o ponto em comum de falar sobre a auto-ilusão do homem (PIRES, 2009).

Por outro lado, no texto Fotografia e fetiche: um olhar sobre a imagem da mulher, Mariana M. Vieira Botti (2003) também realiza uma breve revisão dos sentidos e usos da palavra fetiche, apontando algumas contribuições e críticas à abordagem freudiana. A autora se refere, em primeiro lugar, à acusação de falocentrismo, que denuncia o fato de Freud entender o fetiche como uma "perversão" exclusivamente masculina, relacionada a partes do corpo e/ou vestuário feminino. E, em segundo lugar, ao sentido socialmente mutável dos padrões de normalidade que determinam as práticas consideradas "perversas" ou desviantes. Ela coloca que a noção de fetichismo perdeu hoje um pouco do caráter perverso que possuía anteriormente. No senso comum, diz a autora,

Um fetiche significa apenas uma fantasia sexual capaz de estimular o desejo, construindo noções de pseudo-erotismo e sexualidades dissimuladas. 0 que pode tornar-se um fetiche nos dias de hoje comporta uma noção culturalmente moldada e particularmente transmitida pelos meios de comunicação, moda, indústria cultural e pornografia, que vendem conceitos de beleza e erotismo e, muitas vezes, são capazes de produzir gostos e práticas em determinados contextos. (BOTTI, 2003, p. 109).

É curioso que, embora a autora reconheça a crítica "falocêntrica" à teoria freudiana sobre fetiche, a própria análise que ela realiza no artigo, onde se propõe investigar "a imagem da mulher fetichizada, socialmente construída enquanto objeto de desejo", compartilha o fato de entender o corpo feminino como aquele que geralmente hospeda o fetiche para o gênero masculino. De objetos vistos como dotados de poder, passamos a sujeitos convertidos em objetos, segundo noções culturalmente moldadas e socialmente transmitidas.

Nesse processo de construção artificial da imagem feminina, os únicos papéis que a estas lhes restariam seriam resistir ou reproduzir. Pelo menos é isto o que a autora parece querer dizer quando afirma que a fetichização da imagem da mulher não ocorreria se ela não consentisse em se tornar fetiche, consentimento que se dá por meio de um processo social "onde a mulher aprende a preocupar-se com sua aparência, remodelando-se em conceitos de vaidade e estética, valorizando-se e sendo valorizada por sua própria imagem de beleza (que, não raras vezes, é a imagem de beleza dos outros)" (BOTTI, 2003, p. 28).

No mesmo texto, Botti (2003) cita muito rapidamente duas autoras que representariam posições opostas no debate gerado no feminismo sobre pornografia: Candida Royalle e Catherine MacKinnon. Embora ela não se coloque explicitamente nesse debate, a ideia da fetichização da imagem feminina pode ser traduzida pela noção de “objetificação", postulada pela vertente antipornográfica do feminismo radical. Como explica Maria Filomena Gregori (2003), os grupos antipornografia eram compostos por mulheres identificadas com uma parcela da comunidade feminista lésbica que não apenas rejeitava o sexo heterossexual por uma questão de escolha sexual, mas também como consequência de uma leitura particularmente determinística sobre a dinâmica de poder das relações heterossexuais.

Considerada um dos ícones do feminismo radical, Catherine Mackinnon apresenta uma análise das relações sexuais como sendo estruturadas pela subordinação, de tal modo que os atos de dominação sexual constituem o significado social do "homem", e a condição de submissão o significado social da mulher (GREGORI, 2003).

Este discurso sobre a opressão, que teve uma enorme visibilidade pública na década de setenta, foi criticado mais adiante por propor um determinismo rígido com implicações bastante problemáticas. Esse "contra-ataque" teve início em uma conferência realizada no Barnard College em Nova York, em 1982, cujos resultados foram publicados por Carol Vance no Livro Pleasure and Danger. Segundo Gregori, no interior da tradição feminista em favor da liberdade sexual, Carol Vance criou uma “convenção” que 
Implica a ideia de que a liberdade sexual da mulher constitui prazer e perigo. Perigo na medida em que é importante ter em mente aspectos como o estupro, abuso e espancamento como fenômenos irrefutáveis envolvidos no exercício da sexualidade. Prazer porque há, no limite, uma promessa no erotismo e na busca de novas alternativas eróticas em transgredir as restrições impostas à sexualidade quando tomadas apenas como exercício de reprodução. (GREGORI, 2003, p. 103).

Segundo Gregori (2003), em um dos artigos da coletânea, a antropóloga Gayle Rubin postula que a complexidade da relação entre o sexo e o feminismo deriva do fato de a sexualidade ser o nexo da relação entre gêneros e muito da opressão nascer, ser medida e se constituir a partir dela. Segundo Judith Butler (2006), a relevância desse artigo foi a de salientar que o feminismo não é o único discurso, nem o mais apropriado, para tratar das relações de poder formadas e reguladas pela sexualidade. Este tipo de formulação teve continuidade nos textos de estudiosas como Ann McClintock, que enfatizam, em contextos pós-coloniais e de Terceiro Mundo, que o gênero não é mais central do que raça ou classe para os propósitos da análise sobre práticas sexuais.

As breves referências aos debates feministas e dos estudos de gênero nas décadas de 1970 e 1980, me interessam especificamente para contextualizar as formulações desta última autora, pois encontramos aí uma análise diferente do fetichismo. Em um texto de 1995, intitulado Couro imperial. Raça, travestismo e o culto da domesticidade, McClintock (2003) analisa a relação sadomasoquista de um casal vitoriano constituído por uma "criada" e um advogado. Perguntando-se pelo significado dos rituais desse casal, a autora propõe uma concepção de fetiche "que vive no limite entre o social e o psicológico" e aposta em uma análise que procura "começar a renegociar uma vez mais a relação entre a psicanálise e a história social, a agência das mulheres e o poder masculino, a domesticidade e o mercado" (MCCLINTOCK, 2003, p. 17). Questionando os retratos condescendentes e pejorativos de Cullwick, a mulher do casal, a criada que "desaparece da narrativa de classe média" em que tudo acontece pela vontade do advogado, McClintock se pergunta pelo tipo de atuação possível em situações de desigualdade social extrema. Em suas palavras:

\begin{abstract}
[...] no que segue, quero questionar uma tendência feminista a ver as mulheres como vítimas não ambíguas, tendência essa que iguala atuação e contexto, corpo e situação, anulando assim a possibilidade de recusa estratégica. Desse ponto de vista, Cullwick seria reduzida a uma serviçal vitimizada, exibida como representação da degradação feminina e do domínio masculino. Se ela não foi uma vítima não ambígua, porém, ela também não foi uma heroína não ambígua da revolta feminina. Suas circunstâncias eram constantemente duras e a colocavam em desvantagem; e no entanto, dentro delas, ela se dedicou a uma permanente negociação de poder, pondo em questão as verdades binárias de dominação e resistência, vítima e opressor. Que fazer da atuação e dos desejos de Cullwick nesses curiosos rituais? (MCCLINTOCK, 2003, p. 20).
\end{abstract}

Sem esquecer as especificidades das cenas e narrativas analisadas por McClintock (2003), nas quais a "parafernália teatral" do sadomasoquismo é tão abundante quanto central no argumento da autora, a proposta de nos perguntarmos pela atuação e os desejos dos sujeitos, principalmente quando esses são retratados invariavelmente como vítimas, pode ser deslocada para outros cenários do espectro social. Assim, de uma concepção do fetiche como autoilusão e do fetichismo como fantasia que leva à objetificação, podemos pensar nos rituais fetichistas como jogos de fantasia que giram em torno de transformações de classe, de raça, de gênero, de economia e de idade.

Se tentarmos levar a sério a proposta de que para entender melhor o sentido de uma prática fetichista é necessário explorar o contexto social em que a mesma encontra significado "e contra o qual se coloca com teimosa recusa", provavelmente outros elementos, além do interesse comercial da revista, surgirão para a análise.

Não pretendo ser tão ousada neste ensaio, primeiro porque provavelmente me faltem todas as informações necessárias, e segundo porque antes deveríamos nos perguntar até que ponto a análise de McClintock (2003) se adapta a práticas que podem ser pensadas 
como fetichistas, mas não no registro sadomasoquista. No entanto, alguns apontamentos podem ser considerados. Pode-se, por exemplo, explorar o sentido dos acessórios utilizados nas fotos - as jóias e a champanhe - dentro do contexto da aviação comercial e para além desta, e postular seu simbolismo de classe e seu potencial "despoluidor".

Como aprofundarei mais adiante, quando questionadas a respeito da "sensação de serem vistas nuas", as aeromoças que participaram do ensaio se referiram à "sofisticação" das fotos e ao profissionalismo da equipe da Playboy, que facilitaram enormemente seu trabalho. Se a pornografia tem sido tradicionalmente interpretada como a parte "suja" do erotismo, como a poluição da arte e da beleza eróticas (DÍAZ-BENÍTEZ, 2009, p. 18) e se o ensino da carreira de aeromoça passa por um disciplinamento constante dos corpos que procura incorporar um ideal de beleza erotizado, mas desprovido de sexualidade9, a sofisticação e a elegância de classe podem ser acionadas para “limpar” o caráter impróprio ou imoral da ação de posar nua para uma revista. Isso porque postular que exista um desejo e uma “aceitação estratégica"10 não significa afirmar que se trata de uma escolha livre de preconceitos, acusações e assimetrias de vários tipos.

E a "história" referida no comentário do blog seria simplesmente mais um componente do fetiche? Certamente, conhecer um pouco mais da situação dessas mulheres contribui de alguma forma para o jogo de fantasia-realidade que suscita o ensaio, pois não é casual que o interesse esteja em exibir aeromoças "de verdade" e não mulheres que "interpretam" esse papel. Por outro lado, deslocando-as do papel protagonista da ação, não estaria se procurando a mesma função

\footnotetext{
9 Se a profissão de aeromoça impõe uma organização espaço-temporal muito particular, regida por uma "submissão" à escala de vôos (CASTELLITTI, 2014), um dos principais espaços de socialização e exercício da sexualidade é o dos pernoites, durante os quais toda a tripulação se hospeda no mesmo hotel e compartilha os mesmos momentos de recreação. Essa é uma das fontes do "estigma" vinculado à profissão, e uma das condições que explica a quantidade de casamentos entre comissárias e pilotos, e comissárias e comissários, apesar do estrito controle mantido pelas autoridades da companhia.

10 Parafraseando a noção de "recusa estratégica" de McClintock (2003, p. 20) no fragmento citado.
}

despoluidora mencionada? Não é mais fascinante - do ponto de vista da divulgação midiática, pelo menos imaginar que elas foram convencidas a realizar as fotos? Passo em seguida à análise do tipo de ação levada a cabo pelas aeromoças, recuperando as diferentes narrativas aqui evocadas e fazendo uma breve referência a algumas concepções contemporâneas de agência presentes em vertentes dos estudos de gênero.

\section{NORMAS, SUJEITOS E AGÊNCIA}

As perguntas colocadas por McClintock (2003) sobre a atuação e o desejo em situações de assimetria, ainda as discussões sobre opressão e transgressão no feminismo, ecoam um movimento político e intelectual mais amplo que, a partir dos anos 1970 , no campo da teoria social, começou exigir a necessidade de repensar a "ação" ou a "prática”. Segundo Sherry Ortner (1984), esse movimento, no qual o feminismo teve um papel protagonista, emergiria a partir de uma forte reação ao estruturalismo e sua dupla negação: do sujeito e da história.

No campo dos estudos de gênero, as críticas à lógica binária implicada na concepção do gênero como uma elaboração cultural do sexo levaram a chamar a atenção para a necessidade de uma teoria do sujeito que levasse em conta o papel dos significados e dos discursos na construção social das pessoalidades e da agência. De acordo com o conceito pós-estruturalista de sujeito, este não pode ser concebido como entidade pré-dada que existe no mundo, pois as subjetividades são efeito de discursos sociais e práticas que devem ser especificados (MOORE, 1994).

Em Deshacer el género (2006), Butler analisa os efeitos produtivos das formas jurídicas do poder e o duplo significado de "sujeição": estar sujeito a um regulamento e estar "subjetivado" por este. Apesar dos importantes créditos à obra de Michel Foucault, Butler vai se afastar do filósofo francês para pensar o gênero como algo mais que o exemplo de uma operação de poder mais ampla, propondo que o gênero requer e institui seu próprio regime regulador e discipli- 
nador. A ideia de que o gênero é uma norma quer dizer que opera dentro das práticas sociais como o padrão implícito de "normalização" (BUTLER, 2006, p. 69).

Neste sentido, o gênero rege a inteligibilidade da ação, tem um status e um efeito que parece ser independente das ações que governa; mas a norma não se confunde com a ação. Deste modo, paradoxalmente, estar fora da norma é, em certo sentido, estar definido em relação a ela. Assim sendo, propor que o gênero é uma norma não significa reduzi-lo a sua expressão normativa, pois ele também pode funcionar como o aparato por meio do qual as definições se desconstroem.

A perspectiva teórica desenvolvida por Saba Mahmood (2005) em seu livro Politics of piety. The Islamic revival and the feminist subject recupera criticamente a teoria do sujeito proposta por Butler, levando em conta que "the iterability of performativity is a theory of agency" (BUTLER apud MAHMOOD, 2005, p. 19). Neste sentido, e como bem aponta Mahmood (2005), no grau em que a estabilidade das normas sociais é função de sua repetida incorporação, a agência para Butler está baseada na abertura de cada repetição e na possibilidade de que esta falhe e seja re-apropriada ou resignificada para outros propósitos que não levem à consolidação da norma.

Após as devidas concessões, Mahmood (2005) aponta o que para ela constitui certas tensões que caracterizam o trabalho de Butler, com o intuito de expandir suas análises para outras problemáticas relacionadas. Principalmente, a antropóloga propõe que, embora Butler reconheça a inevitável relação entre os processos normativos de "consolidação" e "desestabilização", seu concepto de agência é desenvolvido principalmente em contextos em que as normas são resignificadas ou subvertidas. Frente a isso, Mahmood (2005) propõe aprofundar a análise das normas na constituição dos sujeitos em uma direção que permita pensar a agência além do dualismo reprodução -resistência. Em suas palavras:

I would like to expand Butler's insight that norms are not simply a social imposition on the subject but constitute the very substance of her intimate, valorized interiority. But in doing so, I want to move away from an agonistic and dualistic framework - one in which norms are conceptualized on the model of doing and undoing, consolidation and subversion - and instead think about the variety of ways in which norms are lived and inhabited, aspired to, reached for, and consummated. As I will argue below, this in turn requires that we explore the relationship between the immanent form a normative act takes, the model of subjectivity it presupposes (specific articulations of volition, emotion, reason, and bodily expression), and the kinds of authority upon which such an act relies. (MAHMOOD, 2005, p. 23).

Nesta chave teórica e por meio da descrição etnográfica de um movimento urbano de mulheres ligadas a uma mesquita, que faz parte do fenômeno mais amplo do Revivalismo Islâmico no Egito, Mahmood (2005) explora o dilema que apresenta para a análise feminista uma configuração em que a subordinação das mulheres às virtudes femininas aparece como condição necessária para sua participação pública na vida religiosa e política.

Neste sentido, seu interesse é trazer esse material para questionar os pressupostos liberais normativos sobre a natureza humana, que informam noções de agência focadas na autonomia moral e política dos sujeitos - como as do próprio feminismo. Recuperando criticamente as contribuições de Janice Boddy, Lila Abu-Lughod e Judith Butler, Mahmood (2005) insiste que o significado da agência deve ser explorado dentro da gramática dos conceitos em que reside, mantendo seu significado em aberto, observando sua emergência em redes institucionais e semânticas que definem e possibilitam formas particulares de relação (MAHMOOD, 2005, p. 34).

Pensar a agência em contextos de desigualdade requer não somente pensar o gênero em sua interação com outros marcadores sociais da diferença, como raça, classe social, idade etc., como também questionar nossos próprios pressupostos sobre o que pensamos quando pensamos em agência. Como coloca McClintock (2003), esse tipo de análise não ignora nem subestima as assimetrias de todo tipo, constitutivas de qualquer experiência social. Trata-se antes de trazer para a superfície os desejos, estratégias e 
escolhas dos sujeitos geralmente vitimizados e silenciados, com o intuito de levar completamente a sério as condições sociais das práticas e das falas.

Deste modo, assim como práticas fetichistas podem emergir como rituais de conversão em que o trabalho de invisibilidade é convertido em reconhecimento e a negação em agência, diferentes capacidades de agência podem ser observadas nos diversos modos de habitar as normas que, a partir de específicas condições históricas e culturais, podem efetuar mudanças no mundo e em si mesmo.

\section{A SUBJETIVIDADE DAS "VIITIMAS"}

Existem dois grandes imaginários vinculados à profissão de aeromoça que, apesar de atribuíveis às transformações por que tem atravessado a aviação comercial no mundo desde os anos 1960, ainda hoje povoam conjunta e contraditoriamente o senso comum. Um é o imaginário da "liberdade", que concebe as aeromoças como mulheres jovens, bonitas e independentes, que recebem um bom salário para viajar pelo mundo inteiro. Esse imaginário está em geral vinculado a um discurso moralizador sobre a conduta sexual dessas mulheres, pois se trataria de uma profissão que favorece a "promiscuidade" e a libertinagem sexual. 0 outro imaginário é o da "servidão": treinadas para sorrir e servir com elegância, as comissárias de bordo seriam como "garçonetes de luxo"11.

Esses registros imaginários se encontram em um discurso crítico que denuncia a manipulação comercial de que são alvo os corpos dessas mulheres, quando as empresas de aviação comercial utilizam a erotização da imagem das aeromoças como estratégia de marketing. Por exemplo, sob o título "uma profissão generizada”, a bloggeira Lola Aronovich escreveu uma crônica, apontando as assimetrias de gênero características da profissão. Para fechar o texto, Lola utiliza um anúncio de uma companhia que, sob o título Explore the backyard of Malaysia apresenta uma foto de cinco comissárias abraçadas, de costas para a

11 A expressão é da bloggeira Lola Aronovich na crônica citada a continuação. câmera, com um evidente foco em seus quadris, como "um dos inúmeros exemplos de como as empresas sexualizam comissárias de bordo [...] até hoje"12.

Parece-me ser este o tipo de leitura que foi difundido sobre a participação das aeromoças no ensaio fotográfico para a revista Playboy. Como a própria Lola escreve, "não é coincidência que uma das profissões mais generizadas que existem também seja uma das mais transformadas em fantasia sexual masculina"; não é coincidência, poderíamos então afirmar dando continuidade a essa lógica, que uma revista erótica masculina queira obter um benefício econômico dessa fantasia sexual "utilizando" aeromoças em suas fotos. Tudo isso faz sentido.

O problema desse tipo de leituras é que chegam a impor uma suposição sobre as subjetividades das muIheres que realizam essa ação, que na prática leva a negar a subjetividade, sem na verdade saber nada sobre seus motivos e vontades. As aeromoças, sendo seres habituados a servir, teriam sido "utilizadas" mais uma vez, vítimas de sua condição de desemprego, praticamente obrigadas a "tirar a roupa". Em se denunciando uma prática "sexualizadora", que supostamente transforma corpos em objeto de desejo, não se faz mais que transformar os sujeitos em objetos sem desejos.

Finalmente achei, procurando outros materiais vinculados ao ensaio fotográfico, uma transcrição de um "bate-papo" do site Uol, realizado no dia 14 de setembro de $2006 \mathrm{com}$ a participação de duas das aeromoças do ensaio ${ }^{13}$. Essa foi a primeira fonte que abordava diretamente o discurso das aeromoças, por meio de uma conversa na qual elas eram indagadas sobre seu passado na Varig, seu presente após a demissão e seu futuro, seus gostos e dificuldades em relação às fotos etc. Questionadas sobre a forma que assumiu o "convite” para realizar o ensaio, Patrícia e Sabrina explicaram que foram indicadas por amigos comissários que tinham contato com a revista. Mais adiante, mencionam

12 Disponível em: http://tc.batepapo.uol.com.br/convidados/arquivo/ sexo/patricia-e-sabrina-ex-aeromocas-da-varig-e-capas-da-playboy-de-setembro.jhtm. Acesso em: 9 maio 2017.

13 Disponível em: http://escrevalolaescreva.blogspot.com.ar/2011/09/ uma-profissao-generizada.html. Acesso em: 9 maio 2017. 
que a ideia surgiu da Playboy, que há muitos anos tinha o interesse de fazer fotos com comissárias, mas que, antes da demissão, elas não podiam aceitar, porque iriam descumprir obrigações contratuais com a Varig.

Em relação à repercussão das fotos, elas expressaram que o ensaio despertou vaidade; mas que muitas mulheres compraram a revista e participaram nas sessões de autógrafos. Falaram ainda da recepção entre colegas da Varig, que foi positiva, porque o ensaio abriu as portas para outros, como o comissário Erick Lobão, que fez fotos para a G Magazine. Questionadas sobre seu estado civil, afirmaram estar casadas com ex-comissários, que as apoiaram “em tudo”. Patrícia mencionou inclusive que seu marido participou como fotógrafo oficial da divulgação da revista. Sobre seu futuro profissional, Sabrina disse querer aproveitar todas as oportunidades que surgissem para seguir a carreira de modelo, continuar a faculdade de Relações Internacionais e retomar o estudo de línguas estrangeiras, "que fala fluentemente”. Patrícia, formada em turismo, tinha planos de fazer um mestrado na área.

Neste sentido, o ensaio era para elas uma chance de abrir outras oportunidades, de mostrar "que somos poliglotas" e - eu agregaria - que são bonitas, têm "boas medidas"; qualidades mais que importantes no mundo da moda.

\section{CONSIDERAÇ̃̃ES FINAIS}

A dificuldade de se pensar a agência implicada nessa situação radica, a meu ver, no fato de que ela se dá em um contexto tradicionalmente denunciado por seu caráter “objetificador”. Segundo o apontado anteriormente, entendendo a liberação sexual como mera expressão dos privilégios masculinos, a participação em um ensaio fotográfico para a revista Playboy não constituiria mais do que uma reprodução dessa estrutura de dominação. No entanto, prestar atenção às subjetividades das mulheres não quer dizer, em primeiro lugar, postular nenhum tipo de questionamento ou resistência a essa lógica. Pelo menos não no sentido de uma subversão direta de normas hegemônicas.
Prestar atenção às subjetividades requer, nas palavras de Adriana Piscitelli (2013, p. 238),

[...] situar suas experiências na interconexão dos processos materiais e simbólicos nos quais se conformam os sistemas de gênero translocais. Isso quer dizer considerar a posição social dessas mulheres nas hierarquias múltiplas de poder que operam dentro e através dos diferentes territórios.

Desse modo, será possível reconhecer que a realização das fotos teve sim um interesse econômico, com objetivos que iam além da contraprestação em dinheiro e que tinham a ver com uma vontade de reconversão profissional. Claro que não deixa de ser uma ação de risco que, como Díaz-Benítez observa em relação às atrizes de filmes pornôs, se insere no espaço de uma produção excluída dos padrões culturalmente aceitos do "gosto legítimo", que pode ter significado uma infração às expectativas sociais e morais que imperam em seus núcleos mais próximos de referência. Parece-me que isso contribui para explicar a necessidade despoluidora de acentuar o caráter "sofisticado" do ensaio, assim como assinalar o apoio recebido pelos maridos.

Em todos esses sentidos, concordo com Díaz-Benítez (2009, p. 23) quando acredita "não haver na pornografia, sobretudo na heterossexual ou mainstream, uma ideologia ou intenção deliberada de violar tabus morais. 0 que não significa dizer que não haja transgressão”. O caráter transgressor da ação, neste caso, parece residir no fato de ir além dos limites da normatização do corpo e da sexualidade impostos pela profissão, utilizando em benefício próprio uma erotização que normalmente é manipulada para fins comerciais. Deve ser levado em consideração que o corpo da aeromoça é alvo de estrito controle e disciplinamento durante o aprendizado da carreira (CASTELLITTI, 2014). A altura e o peso, além da apresentação pessoal, são avaliados desde a primeira entrevista até o final da carreira, assim como o uniforme, o penteado e a maquiagem.

Na Varig, durante os anos 1990, chegou a ser implementado o "Programa Vigilantes do Peso", atendendo a questões estéticas e com o objetivo de propi- 
ciar a "reeducação alimentar" dos funcionários. Com o iminente fim da companhia, o que impedia "investir" esses recursos em outros espaços, se isso ainda permitia ampliar as expectativas laborais? Claro que tinha um custo, pois além da repreensão moral, elas sabiam que realizando as fotos estavam abrindo mão de sua carreira como aeromoças na Varig - se é que ainda the restava alguma possibilidade de recuperação -, e provavelmente em qualquer outra companhia ${ }^{14}$.

Para finalizar, podemos recuperar a noção de "limites da sexualidade" proposta por Gregori (2010), para pensar práticas que, como as aqui analisadas, são indicadoras de um processo social bastante complexo relativo à ampliação ou restrição de normatividades sexuais. Como já disse, não me interessa propor que as fotos realizadas pelas aeromoças constituam uma ação de resistência ou contestação das normativas vinculadas à heterossexualidade como modelo compulsório. Os limites da sexualidade são inteligíveis apenas se concebidos em contextos precisos (GREGORI, 2010, p. 24). Se essa ação por um lado significou a transgressão de um tipo de erotização imposto por uma lógica institucional, permitindo a ampliação das expectativas profissionais colocadas em xeque pela falência da empresa, por outro lado implicou o risco de apostar em um espaço com um caráter "poluidor", infringindo expectativas sociais e morais.

A falência da Varig deixou grande parte de seus funcionários em condições críticas, com mais de cinquenta anos de idade, sem mercado de trabalho que os absorvesse nem idade suficiente para solicitarem aposentadoria. Nesse contexto específico, ser muIher, branca, loira, com menos de trinta anos de idade e um "corpo bonito", podia significar certa vantagem relativa que, sendo bem utilizada, permitiria maiores opções de reinserção profissional.

Por outro lado, a revista Playboy possui certo status vinculado à "fotografia de glamour", que a coloca em uma posição superior em relação a outras

14 Neste sentido, um dos participantes do bate-papo chegou a perguntar se elas aceitariam o convite para voltar a trabalhar como aeromoças, frente ao que elas responderam: "a gente teria que mandar currículos, mas, com a revista, dificilmente vamos voltar a voar". produções do mundo da pornografia. Todos esses elementos nos permitem pelo menos complexificar a imagem das aeromoças como vítimas transmitida pela recepção mediática do ensaio fotográfico. Imagem que coloca em segundo plano as protagonistas da ação, eliminando toda possibilidade de prazer, de "aceitação estratégica" e, dessa forma, subtrai de antemão qualquer potencial transgressor da ação, por mínimo e específico que seja.

\section{REFERÊNCIAS}

CASTELLITTI, C. Corpo e disciplina na carreira de comissária de bordo na Varig. Seminário Interno dos Alunos do PPGAS/MN, 2014, Rio de Janeiro. Anais [], UFRJ, 2014.

BOTTI, Mariana Meloni V. Fotografia e fetiche: um olhar sobre a imagem da mulher. Cadernos Pagu, Campinas-SP, v. 21, Núcleo de Estudos de GêneroPagu/Unicamp, p. 103-131, 2003

BUTLER, Judith. Deshacer el género. Barcelona: Paidós, 2006.

díAZ-BENíTEZ, María Elvira. Nas redes do sexo: bastidores e cenários do pornô brasileiro. 2009. Tese (Doutorado em Antropologia Social) - PPGAS-MN/ UFRJ, Rio de Janeiro, 2009.

DUARTE, Luiz Fernando D.; GOMES, Edlaine. Três Famílias: identidades e trajetórias transgeracionais nas classes populares. Rio de Janeiro: Editora FGV, 2008.

GREGORI, Maria Filomena. Relações de violência e erotismo. Cadernos Pagu, Campinas-SP, v. 20, Núcleo de Estudos de Gênero-Pagu/Unicamp, p. 88-120, 2003.

GREGORI, Maria Filomena. Limites da sexualidade: violência, gênero e erotismo. In: Prazeres perigosos: erotismo, gênero e limites da sexualidade. Tese de livre docência, Campinas-SP: Unicamp, 2010. 
MOORE, Henrietta. The problem of explaining violence in the Social Sciences. In: GOW, Peter; HARVEY, Penelope (ed.). Sex and Violence - Issues in Representation and Experience. New York: Routledge, 1994.

MAHMOOD, Saba. Politics of piety: the Islamic revival and feminist subject. Princeton: University Press, 2005.

MCCLINTOCK, Anne. Couro Imperial. Raça, travestismo e o culto da domesticidade. Cadernos Pagu), Campinas-SP, v. 20, Núcleo de Estudos de Gênero-Pagu/Unicamp, p. 7- 85, 2003.
ORTNER, Sherry B. Theory in anthropology since the sixties. Comparative Studies in Society and History, v. 26, n. 1, p. 126-166, 1984.

PIRES, Rogério Brittes W. 0 conceito antropológico de fetiche: objetos africanos, olhares europeus. Dissertação (Mestrado em Antropologia Social) PPGAS-MN/UFRJ, Rio de Janeiro, 2009.

PISCITELLI, Adriana. Trânsitos: brasileiras nos mercados transnacionais do sexo. Rio de Janeiro: Eduerj, 2013. 